\title{
Effectiveness of Health Education Among Mothers to Reduce Unintentional Home Injuries of Under- Five Year Old Children in Rural Community
}

\author{
Yasir Nouman \\ Lahore School of Nursing, The University of Lahore, Lahore, Pakistan \\ Supervisor \\ Muhammad Hussain, \\ Lahore school of Nursing, The University of Lahore \\ Co supervisor \\ Iram Majeed \\ Dept. Lahore School of Nursing, The University of Lahore, Lahore, Pakistan \\ Head of Department \\ Muhammad Afzal \\ Lahore school of Nursing, The University of Lahore
}

\begin{abstract}
Background: Unintentional home injuries are common in children. Unintentional home injuries are main causes of disability, morbidity and mortality in children, results show that every year 630,000 children died due to unintentional home injuries. Unintentional injuries occur in homes due to lack of awareness and due to improper knowledge, attitude and lifestyle of primary caregiver in homes. Aim of study: The aim of study was to assess the effectiveness of health education among mothers to reduce unintentional home injuries of under-five year old children in rural community. Method: A study design was quasi experimental, one group pre and post test design was used and data was collected at Ali Raza Abad community, Raiwand Road Lahore. Convenient sampling technique was used. Sample size was 71 community mothers who have children under 5- year of age with age group 18 to 45 years. Data was collected by administering knowledge and practice questionnaire before and after the health education programme. Results: The current study shows that the overall mean score of pretest is .4907 and overall mean score of post-test knowledge was .8422. The overall mean score of pretest was .4930 and overall mean score of post-test practice was .8003. These results show that health education is effective to enhance the knowledge and safety practice of mothers. Conclusion: Unintentional home injuries are commonly occur in children and unintentional home injury is also a global health issue in communities. Health education is very important to enhance the general knowledge and safety practice of mothers toward home injuries. On community level health education program is effective to improve the knowledge and safety practice of mother.
\end{abstract}

Keywords: Effectiveness, Health Education, Mothers and Under Five - year old Children, Rural Community. DOI: $10.7176 / \mathrm{JHMN} / 58-03$

\section{Introduction}

Unintentional home injuries are interaction between individuals, their social and physical environment. More than 5 million people die each year as a result of unintentional injuries. This report shows that a total account of death in world is $9 \%$ and home injuries are common in children under five year of age group (World Health Organization, 2014). According to injury report, 30,000 cases of home injuries lead to death every year in United States (Gielen, McDonald, \& Shields, 2015). Worldwide unintentional injury in children is a very common and vital public issue. It is a major cause of death in children and is responsible for disabilities in under-five year old children (Watson \& Errington, 2016). Injury experts recommended the use of community surveys and health education which increasing the knowledge, attitude and practice of mothers on unintentional child injuries in low and middle-income countries (Pant et al., 2015). In Pakistan unintentional home injuries in children under age of five year was the $3 \mathrm{rd}$ most common cause of death (11\%) after diarrhea illness (18\%) and pneumonia $(17 \%)$. Drowning $(22 \%)$, burns $(11 \%)$ and falls $(10 \%)$ were the commonest injuries with mortality two time greater in rural community as compare to urban community areas due to lack of awareness (Razzak, Khan, Zia, \& Azam, 2013). Unintentional injuries are subset of injuries in which there was no evidence of preplan occurrence of injuries, further more in winch include different injuries like drowning, suffocation, burns, poisoning, falls, and physical injuries etc (Salam et al., 2016). Home safety education and safety in equipment use (in kitchen, living rooms and bath rooms) is effective to reduced home injuries in children. Health education 
is also important to increased safety behaviors and awareness in community people which help to reduce unintentional home injuries. So health education is effective way to enhance the knowledge of community people toward safety measure (Kendrick et al., 2013). Children environment and maternal behavior is important to reduce the unintentional injuries at homes. Effective educational program enhance the mothers knowledge towards home injuries. Because supervision and awareness is important to reduce the risk factor in environment where children play. So, positive maternal behavior towards children environment is important for the health and wellbeing of children's (Kuhn \& Damashek, 2014). Health education is very important to enhance the general knowledge of mothers toward home injuries. On community level, health education program is effective to improve the knowledge of mothers. By the help of health education mothers can modify the home condition and use safety measure to protect their child from home injuries. Home safety health education is associated to reduce the injury rates in children at home. Because unintentional home injuries are preventable and proper understanding of these injuries enable mothers to take action to reduce home injury risk in children under five year of age (Zimmermann et al., 2014).

\subsection{Aim of the study}

The aim of the study was to assess the effectiveness of health education among mothers to reduce unintentional home injuries of under-five year old children in rural community.

\subsection{Significance of the study}

The study is significant to minimize unintentional home injuries among under- five year old children in community. After giving health education to mothers the awareness of mother regarding unintentional home injuries become increases, after that the rate of unintentional home injuries and cost of injury burden in community decreases. After giving health education, health of children improve and budget of community people for home injuries will decrease.

\section{Literature}

A study conducted among mothers of under-five year children in Damascus had reported 23.2\% incidence of unintentional injuries in children. This study shows that to avoid unintentional home injuries in children requiring effective health education and counseling to mothers including home safety management (Punyadasa \& Samarakkody, 2016). A study show that there were different factors which cause injuries in under-five year old children like poor condition of kitchens, garden, bathrooms and living rooms. Unintentional home injuries are due to inevitable events, interrupted supervision and lack of home safety knowledge. So, teaching and educational programme are important to enhance the knowledge of mothers towards home condition which increase the risk of child injuries (Kemp, Jones, Lawson, \& Maguire, 2014). Worldwide unintentional home injuries becoming a major cause of death in children, it could be minimized or prevented through measures that could be taken by parents at home. So, health education is so essential for mothers to control risk and eliminate hazards from the environment of under-five year old children. So training should be given to parents especially mothers on risk factors to prevent home accidents (Debnath \& Reang, 2014). There is little evidence that interventions are effective in reducing the incidence of home injuries in children. More evidence was found that educational inventions are effective in promoting safety education to mothers. Some other evidence was found that, the effectiveness of interventions on the safe handling of hot food or drink as compare to kitchen safety practices (Zou et al., 2015). A study literature supports the effectiveness of family-focused prevention programs in community settings. These prevention programs improve the behavior of mothers. Although well-structured studies in primary care settings are needed to develop the effects on child outcomes in rural communities. Therefore, the evidence-based family-focused prevention programs should be beneficial for community people for better outcomes (Leslie et al., 2016). Mother's education along with firm guidance is the key to prevent accidents and safe living. The health education to parents is important to promoting safety in under-five year's children. Health education is also important that help to avoid potential dangers for young children in the home and surroundings. Mother's knowledge and practice plays very important role in preventing home injuries in children (Pradeep M Suryawanshi1, 2016). The prevention of home injuries has been attempted through counseling and health education by home visits and supervision of safety equipment. In some extent, the spreadness of injury prevention information is neglected which increase the rate of home injuries. Based on the findings of this study, it can be strongly recommended that home visits related to identification of injury risks and health education by the root level health care providers need to be considered as essential strategies for preventing unintentional injury in this communities (Banerjee, Paul, Bandyopadhyay, \& Dasgupta, 2016).

\section{Method}

3.1Setting

This study was conducted in community Ali Raza Abad, Raiwand Road, Lahore. 


\subsection{Research Designs}

The quasi-experimental study design was use in this research.

\subsection{Population}

The target population for this research includes mothers of under- five year old children of Ali Raza Abad community.

\subsection{SAMPLING}

Convenient sampling was use in this study.

\subsection{Research Instrument}

A well developed questionnaire on knowledge and safety practice checklist(Ihalahewage et al., 2018) were use to assess the knowledge and practice of participant before and after interventions.

\subsection{Data collection Procedure}

The data collected through questionnaire and practice check list. The pre data collected through questionnaires which save as baseline and then, education session conducted in group at natural home settings. In this way 4 groups entertained consisting of 15 to 18 mothers. The interventions done for four weeks. After that, data collected again from mothers of under five year children on unintentional home injuries.

\subsection{Analyze Data}

- Data analyzed by using SPSS version 21.0 statistical software for data analysis.

- Demographic data has shown in percentage, frequency and standard deviation by using bar charts.

- Effectiveness of intervention assessed by comparing the pre and post data separately by using the parried $t$ test.

\subsection{Study Time Line}

This study took approximately 4 months (from September 2018 to December 2018).

\subsection{Ethical Consideration}

The ethical rules of research study set by the ethical committee of the Lahore school of Nursing followed while conducting the research and the rights of the research participants preserved.

- Written informed consent was taken from all the participants.

- All information and data collection were kept confidential.

- Participants remained unappear throughout the whole study.

- It has informed to participants that they will be free to withdraw at any time there are no disadvantages or risk on the procedure of the study

\section{Results}

This section presents the outcomes of the study. This chapter includes two portions of analysis. First analysis was done of demographic data. It gives detail of 5 demographic questions. Descriptive analysis was used to find out the distribution of each characteristic. Demographic characteristic were Age, Education, Employed, Caregiver and Income Level of participant 
Demographics

\begin{tabular}{|c|c|c|c|}
\hline S\# & Demographic Characteristic & $\mathbf{N}$ & \%age \\
\hline & & 71 & $100 \%$ \\
\hline 1 & \multicolumn{3}{|c|}{ Age Group } \\
\hline & $19-25$ year & 35 & $49.3 \%$ \\
\hline & 26-35year & 33 & $46.5 \%$ \\
\hline & 36-47year & 3 & $4.2 \%$ \\
\hline 2 & \multicolumn{3}{|c|}{ Qualification } \\
\hline & Illiterate & 23 & $32.4 \%$ \\
\hline & Primary- Middle & 21 & $29.6 \%$ \\
\hline & Metric & 23 & $32.4 \%$ \\
\hline & Higher Education & 4 & $5.6 \%$ \\
\hline 3 & \multicolumn{3}{|c|}{ Employed } \\
\hline & Yes & 10 & $14.1 \%$ \\
\hline & No & 61 & $84.9 \%$ \\
\hline 4 & \multicolumn{3}{|c|}{ Caregiver } \\
\hline & Only Mothers & 71 & $100 \%$ \\
\hline & Other Caregiver & 0 & $0 \%$ \\
\hline 5 & Income Level & & \\
\hline & $10,000-35,000$ & 71 & $100 \%$ \\
\hline & Above 35,000 & 0 & $0 \%$ \\
\hline
\end{tabular}

Table 1

\section{Knowledge \& practice}

This section of results shows the knowledge and practice of of participents. Table 1.1 show the (pre and post ) knowledge and practice of participent.

\begin{tabular}{|l|c|c|}
\hline & Mean & Std deviation \\
\hline $\begin{array}{l}\text { Knowledge } \\
\text { Pre knowledge }\end{array}$ & $\mathbf{. 4 9 0 7}$ & $\mathbf{2 5 9 7 9}$ \\
\hline Post knowledge & $\mathbf{. 8 4 2 2}$ & $\mathbf{2 2 1 0 5}$ \\
\hline $\begin{array}{l}\text { Practice } \\
\text { Pre practice }\end{array}$ & $\mathbf{4 9 3 0}$ & $\mathbf{. 0 5 9 7 2}$ \\
\hline Post practice & & $\mathbf{. 0 8 9 6 5}$ \\
\hline
\end{tabular}

\section{Table 1.1}

\section{Knowledge}

In pre-knowledge the overall mean of $n=71$ participant was .4907 with standard deviation .25979 and in postknowledge the overall mean was .8422 with standard deviation .22105 . The knowledge of participants before intervention was not enough but after intervention the knowledge became increase. This shows that health education was effective.

\section{Practice}

In pre practice the overall mean of $n=71$ participant was .4930 with standard deviation .05972 and in post practice the overall mean was .8003 with standard deviation .08965 . Similarly, in the case of practice the level of practice before intervention was not enough but after intervention the practice level became increase. This shows that health education was effective. 


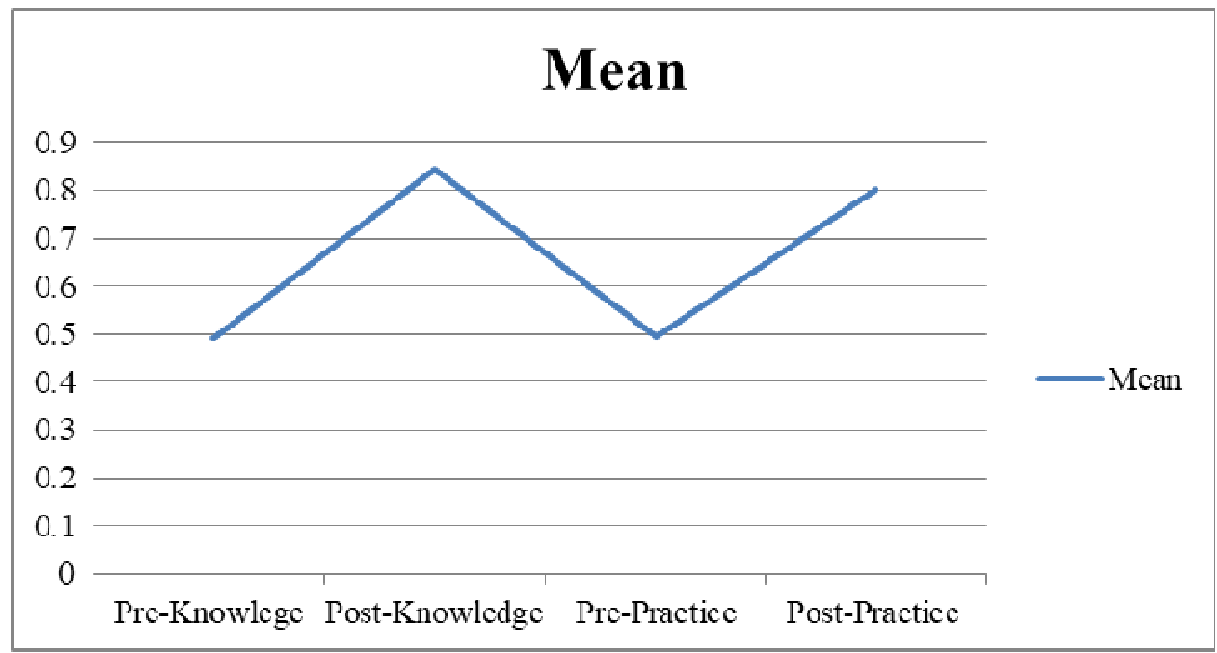

Figure 1.

In figure 1. Show the knowledge and practice (pre-post means) in lines which were incresing. So, the intervetion were effective bacause after the health eduaction sessions the men of the knowledge increae significantly.

\section{Discussion}

A quasi experimental pre and post study design is used to assess the effectiveness of health education among mother of under-five year old children. Current study showed that health education is so effective to bring the change in knowledge and safety practice among mothers of under under-ive year of old children. In pre data, which show that mothers have poor or not enough knowledge and safety practice, but after 4 week interventions knowledge and safety practice improve among mothers which showen by post data. Similar study results shows that educational intervention and home. Visits had an significant effect to reduce home injuries in under-five year old children. Health education significantly improves the knowledge and had a significant effect on mothers' awareness toward their child. This study also showed that $30 \%$ of all unintentional injuries among children can be prevented after educational intervention(Carlsson, Dykes, Jansson, \& Bramhagen, 2016). A study shows that the knowledge of mothers in preventing household unintentional injuries had increased after 1 month interventions compared to before intervention. This shows that, effective health education intervention and training programs had increased mothers' knowledge in preventing unintentional home injuries (RezapurShahkolai, Afshari, Moghimbeigi, \& Hazavehei, 2017). Another study shows that effective health education and teaching is important to avoid children from home injuries. Over all pretest knowledge on prevention of household injuries among mothers of toddlers was average which recommend there is need for structured teaching programme for mothers of regarding prevention of household injuries among under-five year children. Post test result shown the significant improvement in the level of knowledge regarding prevention of household injuries among under-five year children. It can be concluded that teaching the mothers of toddlers to improve the knowledge regarding prevention of unintentional home injuries (Devulkar Namrata1, 2014). A recent study results shows that intervention base health education is effective to enhance the knowledge, attitude and practice of mother. because after getting model based health education the knowledge and preventive behavior of mothers improved.(Rezapur-Shahkolai et al., 2017) A study shows that the highly educated mothers give less attention to their child as compare less educated. So its need to educate them about safety of child. But current study is effective to enhance the knowledge of low educated mother live in rural community. Because health education in important to improve Kowledge and practice of rural community mothers. In pre data mothers had less knowledge but after intervention knowledge and level of practice improve which reveal the effectiveness of health education (Halawa et al., 2015).

\subsection{Limitations:}

1. The sample was limited to only 71 students, the findings could not be generalized on others geographical areas and shortage of time.

2. The sample used for study belongs to one rural community.

3. No attempt was made to follow-up to measure the retention of knowledge and practice after the post-test.

4. This study is also limited due to lack of resources and shortage of time.

\subsection{Recommendation}

1. A similar study can be repeated on a larger sample covering the entire community population in Lahore as 
well as others parts of the country.

2. A similar study can be conducted among rural and urban communities of country.

3. An experimental study can be undertaken with a control group to increase the validity of results.

4. A comparative study may be undertaken on low economic status community and high economic status to compare the knowledge \& practice of mothers under five year old children.

5. Health education should also be given to other caregivers of family to enhance knowledge of other caregivers

6. Proper safety precaution should be used at homes to safe children from unintentional home injuries.

7. Parents must take care of their childen to avoid them from unintentional home injuries and must have knowledge about things that cause injuries.

\subsection{Conclusion}

Unintentional home injuries are commonly occur in children and unintentional home injury is global health issue in communities. Unintentional injuries also occur in homes due to lack of awareness and due to improper lifestyle of people in homes. Health education is very important to enhance the general knowledge and safety practice of mothers toward home injuries. On community level health education program is effective to improve the knowledge and safety practice of mothers. By the help of health education mothers can modify the home condition and use safety measure to protect their child from home injuries. Home safety health education is associated to reduce the injury rates in children at home. Because unintentional home injuries are preventable and proper understanding of these injury risk enable mothers to take action to reduce home injuries in children under five year of age. Based on the findings of the current study, it is concluded that current study shows that health education is so effective to bring significant change in knowledge and practice among mothers of under under-five year of old children. In pre data, which show that mothers have poor or not enough knowledge, but after 4 week interventions knowledge $\&$ practice increase among mothers which showed by post data.

\subsection{Acknowledgement}

I would like to give special thanks to following personalities who in different ways encouraged me for this research work. First I would like to give thanks to Mir. Muhammad Afzal (Head of department, Lahore School of Nursing, The University of Lahore). Sir Afzal allowed me and encouraged me to do this study. I would like to give special thanks To Sir Muhammad Husain for being my research preceptor. I would like to say thanks to Ms. Iram Majeed, as a community instructor she guide me about this study. I would like to say thanks to all Faculty members of Lahore School of Nursing, my parents, all colleagues and all participants of community. Last but not least, special thanks to management of Lahore School of Nursing, The University of Lahore.

\section{Reference}

Banerjee, S., Paul, B., Bandyopadhyay, K., \& Dasgupta, A. (2016). Domestic unintentional injury of 1 to 5-yearold children in a rural area of West Bengal, India: a community-based study. Tanzania Journal of Health Research, 18(3).

Carlsson, A., Dykes, A.-K., Jansson, A., \& Bramhagen, A.-C. (2016). Mothers' awareness towards child injuries and injury prevention at home: an intervention study. BMC research notes, 9(1), 223.

Debnath, M., \& Reang, T. (2014). A study to assess the knowledge of rural mothers regarding common domestic childhood injuries and home-safety measures adopted by them in west district of tripura, india. J Evol Med Dental Sci, 3(20), 5522-5528.

Devulkar Namrata1, K. U. (2014). A study to assess the effectiveness of structured teaching program on knowledge regarding prevention of household injuries among the mothers of toddlers in selected village of belgaum. Unique Journal of Medical and Dental Sciences.

Gielen, A. C., McDonald, E. M., \& Shields, W. (2015). Unintentional home injuries across the life span: problems and solutions. Annual review of public health, 36, 231-253.

Halawa, E. F., Barakat, A., Rizk, H. I. I., \& Moawad, E. M. I. (2015). Epidemiology of non-fatal injuries among Egyptian children: a community-based cross-sectional survey. BMC public health, 15(1), 1248.

Kemp, A. M., Jones, S., Lawson, Z., \& Maguire, S. (2014). Patterns of burns and scalds in children. Archives of disease in childhood, 99(4), 316-321.

Kendrick, D., Young, B., Mason-Jones, A. J., Ilyas, N., Achana, F. A., Cooper, N. J., . . . Wynn, P. (2013). Home safety education and provision of safety equipment for injury prevention. Evidence-Based Child Health: A Cochrane Review Journal, 8(3), 761-939.

Kuhn, J., \& Damashek, A. (2014). The role of proximal circumstances and child behaviour in toddlers' risk for minor unintentional injuries. Injury prevention, injuryprev-2014-041247.

Leslie, L. K., Mehus, C. J., Hawkins, J. D., Boat, T., McCabe, M. A., Barkin, S., . . Tait, V. F. (2016). Primary health care: potential home for family-focused preventive interventions. American journal of preventive 
medicine, 51(4), S106-S118.

Pant, S., Patel, N. J., Deshmukh, A., Golwala, H., Patel, N., Badheka, A., . . . Mehta, J. L. (2015). Trends in infective endocarditis incidence, microbiology, and valve replacement in the United States from 2000 to 2011. Journal of the American College of Cardiology, 65(19), 2070-2076.

Pradeep M Suryawanshi1, S. T., Simi Elsa Philip3. (2016). A Study to Assess the Effectiveness of Structured Teaching Programme on Knowledge of Mothers Regarding Prevention of Accidents among Preschoolers in Selected Anganwadi at Karad. International Journal of Science and Research (IJSR).

Punyadasa, D., \& Samarakkody, D. (2016). Community-based study on family-related contributory factors for childhood unintentional injuries in an urban setting of Sri Lanka. Asia Pacific Journal of Public Health, 28(1_suppl), 102S-110S.

Razzak, J. A., Khan, U. R., Zia, N., \& Azam, I. (2013). A child an hour: burden of injury deaths among children under 5 in Pakistan. Archives of disease in childhood, 98(11), 867-871.

Rezapur-Shahkolai, F., Afshari, M., Moghimbeigi, A., \& Hazavehei, S. M. M. (2017). Home-related injuries among under-five-year children and mothers' care regarding injury prevention in rural areas. International journal of injury control and safety promotion, 24(3), 354-362.

Salam, R. A., Arshad, A., Das, J. K., Khan, M. N., Mahmood, W., Freedman, S. B., \& Bhutta, Z. A. (2016). Interventions to prevent unintentional injuries among adolescents: A systematic review and meta-analysis. Journal of Adolescent Health, 59(4), S76-S87.

Watson, M. C., \& Errington, G. (2016). Preventing unintentional injuries in children: successful approaches. Paediatrics and Child Health, 26(5), 194-199.

World Health Organization. (2016). regional Action Plan for violenece and Injury Preventio in th the western pacific (2106-2020.

World Health Organization.(2014). Injuries and violence: the facts 2014. World Health Organization.http://www.who.int/handle/10665/149798 